\title{
Future perspectives of anticholinergics for the treatment of asthma in adults and children
}

This article was published in the following Dove Press journal:

Therapeutics and Clinical Risk Management

\section{Roland Buhl' \\ Eckard Hamelmann ${ }^{2,3}$}

'Pulmonary Department, Johannes Gutenberg University Hospital Mainz, Mainz, Germany; ${ }^{2}$ Children's Center Bethel, Evangelic Hospital Bethel, Department of Pediatrics, Bielefeld, Germany; ${ }^{3}$ University Children's Hospital, Allergy Center Ruhr, Ruhr University Bochum, Bochum, Germany

Video abstract

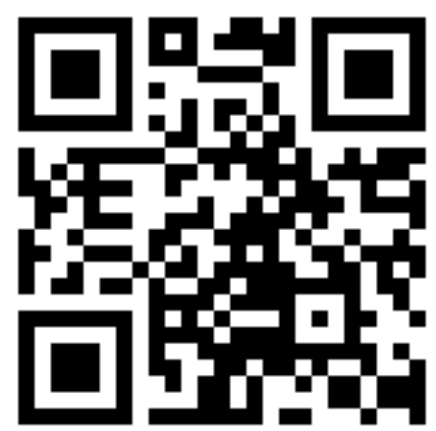

Point your SmartPhone at the code above. If you have a QR code reader the video abstract will appear. Or use: http://youtu.be/0uhMDSFIPRc

Correspondence: Roland Buhl Pulmonary Department, Johannes Gutenberg University Hospital Mainz, Langenbeckstraße I, 55I3I Mainz, Germany

Tel +49613 II7 727|

Email roland.buhl@unimedizin-mainz.de

\begin{abstract}
Despite major advances in therapeutic interventions and the availability of detailed treatment guidelines, a high proportion of patients with symptomatic asthma remain uncontrolled. Asthma management is largely guided by the Global Initiative for Asthma (GINA) strategy and is based on a backbone of inhaled corticosteroid (ICS) therapy with the use of additional therapies to achieve disease control. Inhaled long-acting bronchodilators alone and in combination are the preferred add-on treatment options. Although long-acting muscarinic antagonists (LAMAs) are a relatively recent addition to disease management recommendations for asthma, tiotropium has been extensively studied in a large clinical trial program. In Europe and the United States, tiotropium is approved for patients aged $\geq 6$ years and uncontrolled on medium- to high-dose ICS/long-acting $\beta_{2}$-agonists at GINA Steps 4 and 5 with a history of exacerbations. Evidence supports the efficacy of tiotropium Respimat ${ }^{\circledR}$ in adults in terms of lung function and asthma control, with a safety profile comparable with that of placebo across a range of asthma severities. Similarly, clinical trials in patients aged 1-17 years have shown improvements in lung function and trends toward improved asthma control. Furthermore, its efficacy makes tiotropium relatively easy to incorporate into routine clinical practice, irrespective of allergic status and without the need for patient phenotyping. Tiotropium is a cost-effective treatment that may offer an important alternative to other, more expensive add-on therapies. This review discusses the potential future position of LAMAs in clinical practice by considering the continuously evolving evidence. Prominence is given to tiotropium, the only LAMA supported by a structured clinical trial program in asthma to date, while also considering other recommended treatment options for patients with uncontrolled asthma. The importance of effective patient/caregiver-clinician communication and shared decision-making in enhancing treatment adherence is also highlighted.
\end{abstract}

Keywords: asthma, anticholinergic, tiotropium, LAMA, asthma management, adherence, pediatric asthma

\section{Introduction}

Despite major advances in therapeutic interventions, asthma remains a challenge globally. ${ }^{1}$ The 2016 Global Burden of Disease update reported a global prevalence of asthma of 339 million people and estimated years lived with disability (YLD) as 13 million in 2016, with an increase of 3.6\% in age-adjusted YLD rates in the last decade. ${ }^{2}$ In a European survey, the prevalence of diagnosed asthma in adults across five countries was estimated at $5.8 \%$; of these patients, $\sim 50 \%$ were not well controlled. ${ }^{3}$ In the United Kingdom, it is estimated that over $60 \%$ of adults with asthma being treated with at least an inhaled corticosteroid (ICS) combined with a long-acting $\beta_{2}$-agonist (LABA) (Global Initiative for Asthma [GINA] Step 3) remain uncontrolled. ${ }^{4}$ Similarly, poor levels of asthma control of over $50 \%$ are reported for children and adolescents. ${ }^{5}$ Uncontrolled asthma confers a considerable impact on 
health care systems. Data from the REcognise Asthma and LInk to Symptoms and Experience survey of 8,000 European patients aged $18-50$ years show that, of the $45 \%$ of patients with uncontrolled asthma, 24\% had visited the emergency department and $12 \%$ had been hospitalized over the previous 12 months. ${ }^{6}$ The frequency of exacerbations is a major risk factor for the development of chronic and progressive disease in children and adolescents. ${ }^{7}$

The long-term goals of asthma management are symptom control, minimization of future risk of exacerbations, and reduction of airflow limitation while simultaneously minimizing treatment side effects. ${ }^{8}$ There is a need for more treatment options to allow these goals to be achieved in patients who remain symptomatic with the highest therapy regimens. ${ }^{8}$ This review discusses current recommendations and recent developments in asthma management; it also considers the role of anticholinergic therapy and the future position of long-acting muscarinic antagonists (LAMAs) in the management of asthma across all age groups, while taking into account other recommended treatment options for patients with uncontrolled asthma. The discussion will also include an overview of the evidence to date for the benefits of tiotropium as the most extensively studied LAMA in the management of asthma in adult and pediatric/adolescent patients and the potential impact of these findings for future clinical practice.

\section{Current treatment \\ recommendations for asthma}

The 2018 GINA report ${ }^{8}$ recommends a stepwise approach in the treatment of all patients with asthma, details of which are discussed elsewhere in this review series. ${ }^{9,10}$ Briefly, treatment algorithms are the same for adolescents and adults, recommending initial low-dose ICS with increasing ICS dose and/or other add-on treatments until control is achieved. Until recently, add-on maintenance therapies for these age groups included LABAs and leukotriene receptor antagonists (LTRA). ${ }^{8}$ Therapeutic recommendations differ for children aged 6-11 years, with preference for the use of moderate-dose ICS (double the "low" daily dose over combination ICS/LABA at Step 3). If this strategy is ineffective, it is recommended that the child be referred for expert assessment and advice at further treatment steps. ${ }^{8}$ In children aged $<6$ years, the preferred asthma control medication is low-dose ICS, such as $200 \mu \mathrm{g}$ budesonide or equivalent, plus as-needed short-acting $\beta_{2}$-agonists (SABAs) as reliever medication. However, ICS monotherapy often only confers partial control in children aged $<6$ years and, due to lack of data, treatment options for these patients are limited to doubling of low-dose ICS and addition of an LTRA, with specialist referral required if this strategy fails. ${ }^{8}$

The recent label approval of tiotropium for use in patients aged $\geq 6$ years with severe asthma in both Europe ${ }^{11}$ and the United States ${ }^{12}$ reflects an awareness of the need for effective therapies for this younger population. However, there is still an important unmet clinical need for additional evidence-based second-line therapies in young children with uncontrolled symptomatic asthma.

\section{Recent developments in asthma management}

Asthma management continues to evolve as new treatment options are developed, approved, and incorporated into treatment recommendations. The GINA strategy currently includes the addition of the LAMA tiotropium as a Step 4-5 add-on treatment for patients aged $\geq 12$ years with a history of exacerbations, before escalation to treatment with biologics or low-dose oral corticosteroids (OCS) (where applicable). ${ }^{8}$ An extensive trial program, designed to establish the efficacy and safety of tiotropium Respimat ${ }^{\circledR}$ Soft Mist $^{\mathrm{TM}}$ inhaler (Boehringer Ingelheim Pharma GmbH \& Co. KG, Ingelheim am Rhein, Germany), ${ }^{13-19}$ has helped in the quest to address the unmet need of patients who remain symptomatic despite available therapies, resulting in the label approval in adult patients in Singapore (aged $\geq 18$ years), Japan (aged $\geq 15$ years), and, more recently, in Europe and the United States for patients aged $\geq 6$ years. ${ }^{11,12}$ Given that tiotropium is a well-tolerated and efficacious add-on to at least medium-dose ICS plus one or more controller medications in clinical trials in children aged $<12$ years, ${ }^{17,20,21}$ assessing its use for the treatment of patients aged $<6$ years, in whom alternative controller treatments are limited, could be extremely valuable due to the high unmet medical need in this age group. An increasing number of biologic therapies targeting exacerbations are emerging. Antibody-based therapies are available to treat patients with moderate-tosevere allergic asthma aged $>6$ years, ${ }^{22}$ or for adolescents ${ }^{22}$ and adults, ${ }^{23,24}$ as add-on options at GINA Step 5. Omalizumab (Novartis Pharma Services AG, Basel, Switzerland) is a humanized monoclonal anti-immunoglobulin $\mathrm{E}$ ( $\mathrm{IgE}$ ) antibody initially approved in 2003 for the treatment of moderate-to-severe allergic asthma. By binding to the fragment region of free $\mathrm{IgE}$, it prevents its binding and allergeninduced cross-linking of high-affinity receptors on effector cells. ${ }^{22}$ More recently, the humanized anti- IL-5 monoclonal antibodies reslizumab (Teva UK Ltd, Harlow, UK), 
mepolizumab (GlaxoSmithKline UK, Uxbridge, Middlesex, UK), and benralizumab (AstraZeneca UK Ltd, Luton, Bedfordshire, UK) have been approved for the treatment of severe eosinophilic asthma in adults. ${ }^{25-27}$ Dupilumab (Regeneron Pharmaceuticals, Inc., Guildford, Surrey, UK), ${ }^{28,29}$ which targets the alpha chain of the IL-4 receptor, thereby inhibiting binding of both IL-4 and IL-13, has also demonstrated improved outcomes in adult patients with severe or moderateto-severe asthma, including lung function, exacerbations, and symptoms. ${ }^{30}$ Treatment with biologics requires either subcutaneous or, in some cases, intravenous injections by health care professionals at regular intervals, as IgE levels and eosinophil numbers can be rapidly restored. ${ }^{31}$ Although these therapies have proven safety profiles, important limiting factors include the inconvenience caused to the patient due to the repeated visits for therapy and the personal financial cost of these visits. Their use also requires patient phenotyping and specific biomarker analysis to ensure the appropriate selection of patients who are most likely to benefit from the different biologic options. ${ }^{32}$ This requires additional testing, thereby increasing the complexity of prescribing an already costly therapy. Inhaled therapies offer a more autonomous option for asthma management as well being more cost effective and should therefore be thoroughly explored before considering biologics or OCS as therapeutic options.

\section{Further options for Step 4-5 add-on treatment}

In adults with symptomatic severe asthma with poor control and/or frequent exacerbations despite good inhaler technique and treatment adherence, low-dose OCS may be considered. ${ }^{8}$ However, OCS are frequently associated with substantial side effects after both frequent short-term and long-term use, ${ }^{33,34}$ this may account for the reluctance to prescribe OCS generally, not just in younger, symptomatic severe asthma patients. ${ }^{35}$ Another recommended alternative for symptomatic severe adults is bronchial thermoplasty - a nonpharmacological intervention that claims to reduce the amount of smooth muscle in the airway walls, making it less likely that the airways will become narrow in the future. . $^{8,36}$ Although bronchial thermoplasty has shown some improvements mainly in reducing exacerbations in adults with severe asthma, more long-term evidence from well-controlled clinical trials is required to establish the procedure, particularly in severe asthma. ${ }^{36}$

A subpopulation of adult patients with persistent symptomatic asthma who may benefit from treatment with macrolides has yet to be precisely defined. ${ }^{37}$ Clinical trials with azithromycin found a decrease in exacerbations in patients treated compared with those prescribed placebo, as well as an improvement in asthma-related quality of life. ${ }^{35}$ Macrolides could also be considered another potential treatment to achieve disease control in patients who remain poorly controlled despite optimal inhaled treatment and who do not qualify for biologics. In particular, the effects of long-term therapy with macrolides on community microbial resistance are, as yet, undetermined and remain a major concern.

\section{Cholinergic activity in asthma pathophysiology}

Understanding the role of cholinergic signaling in the airways is important to gain a clear overview of the significance of LAMAs in asthma management. The neurotransmitter acetylcholine $(\mathrm{ACh})$ is released by the parasympathetic nervous system and regulates airway tone, smooth muscle contraction, and mucus secretion. ${ }^{38}$ ACh exerts its effects primarily via interaction with muscarinic $(\mathrm{M})$ receptors on the airway smooth muscle (ASM) ${ }^{38}$ It is postulated that functional antagonism due to crosstalk between $M$ receptors and $\beta_{2}$-adrenoceptors may exert an influence on $\beta_{2}$-agonistinduced muscle relaxation. ${ }^{39}$ Thus, muscarinic antagonists may provide bronchodilation in a way that is both complementary and different to $\beta_{2}$-agonists.

Anticholinergics, both short-acting and long-acting, have long been used in the management of respiratory disease, particularly chronic obstructive pulmonary disease (COPD). Tiotropium has been approved for use in COPD for over 10 years and has the most extensive research available in asthma for a LAMA. As such, its mechanism of action as a bronchodilator is well established in these respiratory diseases. In the airways, tiotropium binds competitively and reversibly to the $\mathrm{M}_{1}$ and $\mathrm{M}_{3}$ receptors on $\mathrm{ASM},{ }^{40}$ inhibiting the action of $\mathrm{ACh}$, thereby indirectly leading to smooth muscle relaxation. ${ }^{40,41}$ Compared with the short-acting muscarinic antagonist (SAMA) ipratropium, tiotropium dissociates much more slowly from the $M_{1}$ and $M_{3}$ receptors, making it a more potent bronchodilator. ${ }^{42}$ Its $>24$-hour duration of action has been confirmed by several clinical studies in COPD. ${ }^{42,43}$

\section{Clinical evidence with anticholinergics}

\section{Short-acting muscarinic antagonists}

Ipratropium bromide is a SAMA that nonselectively blocks $\mathrm{M}_{1}, \mathrm{M}_{2}$, and $\mathrm{M}_{3}$ muscarinic receptors in the airways ${ }^{44}$ and exerts a bronchodilator effect in patients with asthma. ${ }^{45}$ 
Currently, ipratropium is recommended as an alternative reliever agent for adult patients who are unable to tolerate treatment with SABAs. ${ }^{46}$ Significant improvements in bronchodilation after 4 weeks of treatment with ipratropium bromide/albuterol combination therapy compared with albuterol alone were observed. ${ }^{37}$

Ipratropium is often used in conjunction with a SABA for the emergency treatment of exacerbations in adults and children; this approach has been associated with fewer hospitalizations and greater improvement in peak expiratory flow (PEF) and forced expiratory volume in 1 second $\left(\mathrm{FEV}_{1}\right)$ compared with SABA alone. ${ }^{8,47,48}$ For children experiencing a severe asthma exacerbation, triple therapy with ipratropium, albuterol, and an OCS led to significant improvement in lung function compared with standard therapy. ${ }^{45}$

Ipratropium has been shown to be more effective in adults with nonatopic asthma and a longer duration of the disease. ${ }^{49}$ However, Cochrane reviews of the effectiveness of SAMAs in adults and children reveal no advantages to justify their use as maintenance asthma treatments. ${ }^{50,51}$

\section{Long-acting muscarinic antagonists}

\section{Tiotropium bromide}

Data from several clinical trials in patients aged 1-75 years with asthma show that the efficacy of tiotropium is consistent in both adults and children, irrespective of disease severity and phenotype. The trials in the tiotropium clinical development program will be briefly summarized here but are discussed in greater detail in other articles in this supplement.

The efficacy and safety of tiotropium in asthma has been demonstrated in five adult ${ }^{52-56}$ and two pediatric ${ }^{57,58}$ Phase II studies comparing tiotropium with placebo. Tiotropium's safety and safety profile (investigated at doses of 5 and $2.5 \mu \mathrm{g}$, delivered as two puffs once daily via the Respimat ${ }^{\circledR}$ device) vs placebo was further established with a series of four Phase III trials in adults with symptomatic mild, ${ }^{57}$ moderate, ${ }^{14,59}$ or severe ${ }^{13}$ asthma as add-on to ICS \pm LABA (Table 1). Phase II trials in both adults and children were performed using different tiotropium dosages: 5, 2.5, and $1.25 \mu \mathrm{g}$, each delivered as two puffs once daily via the Respimat $^{\circledR}$ device. Across Phase II and III trials, the results of the 2.5 and $5 \mu \mathrm{g}$ doses were predominantly similar, and both were superior to placebo for most endpoints tested. Therefore, based on the Phase II and III trials mentioned above, the approved and recommended once-daily tiotropium Respimat $^{\circledR}$ dose for asthma in adults and children 6 years and above is $2.5 \mu \mathrm{g}$ in the United States and $5 \mu \mathrm{g}$ in almost all other countries. Of note, the $5 \mu \mathrm{g}$ dose was superior to the
$2.5 \mu \mathrm{g}$ dose for some endpoints in both the Phase II and III trials in children with moderate and severe asthma, without any differences regarding safety compared with placebo or the $2.5 \mu \mathrm{g}$ dose. Both doses of tiotropium significantly improved lung function and asthma control. Results from three Phase III studies in children and two in adolescents with symptomatic moderate or severe asthma despite medium- or high-dose ICS also showed that tiotropium Respimat $^{\circledR}$ resulted in a greater improvement in $\mathrm{FEV}_{1}$ within 3 hours postdose $\left(\mathrm{FEV}_{1(0-3 \mathrm{~h})}\right)$ response at 12 and 24 weeks compared with placebo (Table 1). ${ }^{15-19}$ Furthermore, in some cases, patient-assessed asthma control and quality of life did not reach statistical significance or cross the threshold for minimal clinical important difference. In addition to data from company-sponsored clinical trials, data from an independent study by Peters et al support the use of tiotropium for the treatment of asthma in adult patients at GINA Step 3 and $4 .{ }^{60}$ Their findings showed that the use of tiotropium was superior to doubling the ICS dose, with improvements in symptoms and lung function; tiotropium as add-on to medium-dose ICS was also shown to be noninferior to adding salmeterol. ${ }^{60}$

In our experience, some patients believe tiotropium is less effective than LABA therapy due to its slower onset of action. Lung function assessment, however, has demonstrated that tiotropium, as an add-on therapy to LABA, is as effective as size on lung function in terms of timing and effect. ${ }^{53,61}$ Patient compliance, as we have observed it, increases if patients are informed of the difference in onset of action.

Asthma is a complex heterogeneous disease that comprises different phenotypes and endotypes; as such, patients may respond differently to therapies. However, evidence from subgroup analyses of data from clinical studies in patients aged 18-75 years with symptomatic moderate or severe asthma have demonstrated that tiotropium is effective in asthma, irrespective of baseline characteristics and phenotypes. ${ }^{62}$ Similarly, data from subgroup analyses of the two replicate MezzoTinA-asthma ${ }^{\circledR}$ studies have demonstrated that tiotropium's efficacy is independent of baseline characteristics in adults with symptomatic moderate asthma. ${ }^{63}$ Data from studies with tiotropium in children and adolescents with symptomatic moderate or severe asthma also support these findings, and demonstrate treatment efficacy irrespective of eosinophil numbers in peripheral blood or IgE serum levels ${ }^{64-66}$ without the need to phenotype.

Preclinical studies also indicate that tiotropium may have other benefits, such as preventing airway remodeling ${ }^{67}$ and reducing airway inflammation. ${ }^{68,69}$ 


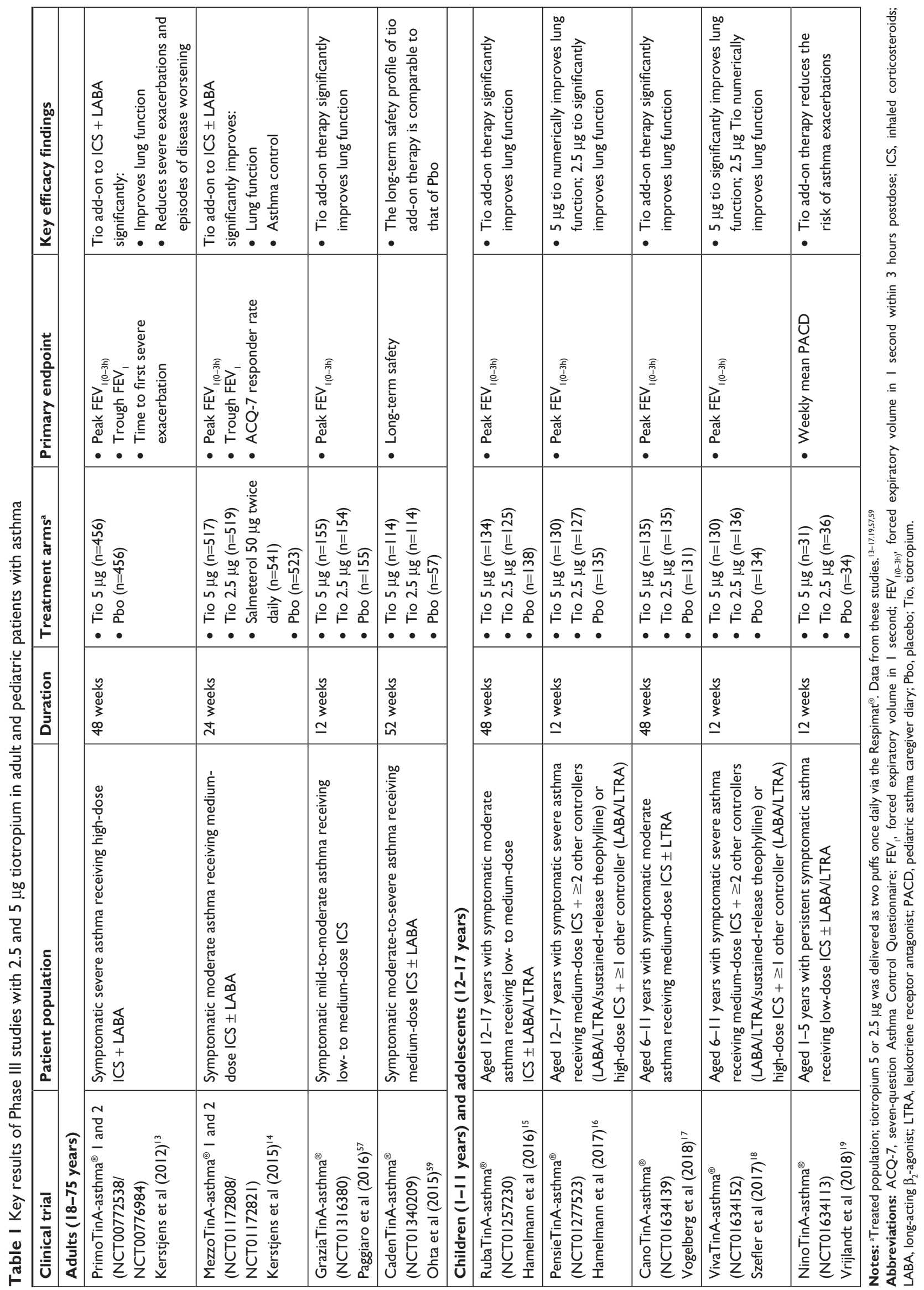




\section{Other long-acting muscarinic antagonists}

To date, the tiotropium clinical trial program in asthma across all age groups is by far the most advanced of the studies evaluating LAMAs. A number of studies assessing the LAMAs umeclidinium bromide (GlaxoSmithKline plc, Middlesex, UK) and glycopyrronium in adults with symptomatic and uncontrolled asthma have been completed or are ongoing. ${ }^{70-75}$ Although both therapies are approved for COPD, neither has been approved for an asthma indication. A Phase II trial investigating the efficacy of umeclidinium monotherapy in adults with asthma showed no conclusive therapeutic benefit. ${ }^{70,71}$ However, a different study in asthma showed that it had potential as a combination therapy with ICS, demonstrating improvements in trough $\mathrm{FEV}_{1}$, morning PEF, and evening PEF. ${ }^{71,72}$ A Phase III study assessing the safety and efficacy of adding umeclidinium to ICS + LABA in adults with symptomatic uncontrolled asthma is also ongoing. ${ }^{73}$ Results from a comparative study showed that both tiotropium and glycopyrronium provided clinically significant bronchoprotection against methacholine-induced bronchoconstriction for up to 96 hours, but at 168 hours, this effect was only significant with tiotropium. ${ }^{74} \mathrm{~A}$ small crossover study investigating the potential utility of glycopyrronium in asthma showed that it significantly prolonged bronchoprotection and bronchodilation compared with ipratropium and placebo. ${ }^{75}$ Another LAMA approved for COPD - aclidinium - is currently under investigation in an acute model of asthma. ${ }^{76}$ Data from a murine model of asthma indicate that aclidinium reduces allergen-induced airway hyperresponsiveness and eosinophilic airway inflammation. ${ }^{77}$ However, there are no clinical trials currently investigating the effect of aclidinium in patients with asthma.

Overall, studies involving patients with asthma investigating the effects of LAMAs other than tiotropium are few in adults and have yet to be commenced in adolescents or children. Therefore, there is limited information to allow conclusions to be drawn about the potential future use of umeclidinium bromide, glycopyrronium, or aclidinium in the management of asthma.

\section{Future perspectives in asthma management}

\section{Asthma in adults}

Prior to the approval of tiotropium for the treatment of asthma, alternative options for adults with severe asthma uncontrolled with ICS/LABA were mainly biologic therapies or OCS. ${ }^{8}$ The use of biologics, while efficacious, requires specific biomarker analysis to phenotype patients, ${ }^{32}$ and long-term use of OCS is associated with a high potential for side effects. ${ }^{8,33,34}$ The large body of data demonstrating the efficacy of tiotropium in the treatment of symptomatic asthma regardless of baseline characteristics addresses a previously unmet need in uncontrolled asthma. Its administration without the need for patient phenotyping makes tiotropium relatively easy to incorporate into routine clinical practice. Of note, GINA strategy now recommends the use of tiotropium as preferred option in adults uncontrolled on ICS/LABA at Step 4 and 5, before the addition of anti-IgE, anti-IL-5, or OCS. ${ }^{8}$

Tiotropium may also provide an alternative option to the use of LABAs in patients with uncontrolled asthma and is currently being investigated as such. In the large Gaining Optimal Asthma ControL study with over 3,000 patients aged 12 to $<80$ years with uncontrolled asthma, around one-third of participants were not able to gain sufficient control despite ICS/LABA treatment. ${ }^{78}$ Additionally, studies in adults have shown that some patients may develop a tolerance to long-term use of LABAs, ${ }^{79,80}$ impairing their efficacy in bronchospasm prevention. There are currently limited treatment options for this group of patients, and evidence suggests that tiotropium has the potential to fill this gap..$^{81,82}$ Findings from a Cochrane meta-analysis of four double-blind, double-dummy studies with $\sim 2,000$ adults, comparing the use of tiotropium vs LABA add-on to medium-dose ICS, show that differences between the two controller medications were small. Tiotropium showed slight benefits over LABA on some measures of lung function, whereas LABA showed benefit in terms of quality of life..$^{82}$ In a second trial, Kerstjens et al confirmed the aforementioned efficacy and safety of tiotropium add-on therapy compared with salmeterol. ${ }^{14}$ Data from the Tiotropium Bromide as an Alternative to Increased Inhaled Glucocorticoid in Patients Inadequately Controlled on a Lower Dose of Inhaled Corticosteroid study in adults with inadequately controlled asthma also show that some patients respond to tiotropium but not salmeterol, and vice versa. ${ }^{83}$ Furthermore, Peters et al have shown that tiotropium is noninferior to the LABA salmeterol in adults with asthma. In that study, the addition of tiotropium to ICS resulted in a greater improvement in $\mathrm{FEV}_{1}$ and PEF compared with doubling the ICS dose. ${ }^{60}$ As the evidence increases, tiotropium may emerge as the key choice in adults for add-on to ICS/LABA, and in those unsuitable or intolerant to treatment with a LABA. The use of LABAs as monotherapy has been associated with increased rates of hospitalization ${ }^{84}$ and 
asthma-related deaths ${ }^{85}$ and has been linked to the occurrence of adverse cardiac events such as tachycardia. ${ }^{86}$

\section{Pediatric asthma}

The indication for tiotropium add-on treatment has recently been expanded to patients in the European Union aged $\geq 6$ years with severe asthma who experienced $\geq 1$ severe asthma exacerbation in the past year, and to patients in the United States aged $\geq 6$ years with asthma. ${ }^{11,12}$ The approval of tiotropium has addressed an important unmet clinical need for children with uncontrolled asthma on ICS/LABA; these patients previously had very limited choices for add-on therapy, with less clear evidence for efficacy and safety, and have thus required specialist referral. Importantly, tiotropium has been demonstrated to be efficacious in pediatric asthma regardless of allergic subtype. Asthma in childhood is often associated with atopy - a condition that predisposes to production of IgE against specific allergens ${ }^{87}$ - and studies have therefore been performed to determine whether baseline $\operatorname{IgE}$ levels or blood eosinophil counts will influence response to tiotropium. Analysis of pooled data from symptomatic moderate patients aged 6-17 years in the CanoTinA-asthma ${ }^{\circledR}$ and RubaTinA-asthma ${ }^{\circledR}$ trials has shown that tiotropium improves lung function irrespective of these markers of an allergic status. ${ }^{64-66}$ These results demonstrate the effectiveness of tiotropium in pediatric asthma, primarily on lung function, without the need for phenotyping according to $\mathrm{IgE}$ levels or blood eosinophil counts, again conferring time- and cost-related benefits in the incorporation of tiotropium into clinical practice. However, while there was a consistent pattern for improved lung function, some improvements at different ages with specific doses did not reach statistical significance. Therefore, further studies investigating the relationship between improvement in pulmonary function, decreased exacerbations and increased quality of life are warranted.

Further consideration should also be paid to the personalization and monitoring of response to step-up therapy in pediatric asthma that is uncontrolled with ICS monotherapy. Differential responses to step-up therapy with ICS, LABA, or LTRA in ICS-treated children aged 6-17 years with uncontrolled mild-to-moderate asthma were demonstrated in the Best Add-on Therapy Giving Effective Responses trial. In this randomized, double-blind, three-way crossover trial, LABA add-on was significantly more likely to provide the best response vs either increased ICS dose or LTRA as add-on. ${ }^{88}$ Importantly, a differential response to the three step-up therapies occurred in $98 \%$ of patients, demonstrating that a single effective combination treatment for all patients does not currently exist in uncontrolled pediatric asthma. Findings from a meta-analysis of 18 randomized trials with $\sim 3,750$ patients aged $\leq 18$ years, comparing the use of LTRA and ICS alone or in combination in mild-to-moderate asthma, show that patients treated with ICS alone had fewer asthma exacerbations and better lung function and asthma control than with LTRA alone. ${ }^{89}$ Add-on LTRA to ICS conferred no significant benefit in this analysis. Furthermore, data from a Cochrane meta-analysis of four randomized trials in almost 560 patients aged 6-18 years with mild-to-moderate asthma demonstrated no significant benefit of adding LTRA to ICS in the three trials that evaluated this treatment. ${ }^{90}$ These data do not support LTRA as a Step 3 add-on in children and adolescents. Collectively, these findings, when considered with the adverse effects on linear growth associated with ICS use in these age groups, ${ }^{91,92}$ favor the use of add-on LABA to ICS as step-up therapy over add-on LTRA or increased ICS use. Tiotropium is an equally effective add-on to ICS and the only LAMA approved for use in children with asthma. It may provide an important alternative for pediatric patients, particularly those who have inadequate response to ICS + LABA. Thus, further responder analyses by age for different therapeutic options are required and should include tiotropium with ICS \pm LABA as a triple therapy.

Tiotropium is a bronchodilator with no anti-inflammatory activities, and this may result in a limited effect size. The effect on future risk, such as exacerbation frequency and severity, was expectedly lower compared with the observed effect on disease control and, more importantly, lung function. Due to this mode of action, tiotropium is to be used as add-on to ICS and not as a single maintenance treatment. The addition of tiotropium to moderate- or high-dose ICS with or without LABA can improve lung function and enhance symptom control, and potentially aid in reducing future risk.

\section{Inhaler considerations}

It is notable that, despite the availability of efficacious therapies and international treatment guidelines, achieving asthma control remains an elusive goal for a high proportion of patients of all ages worldwide..$^{93,94}$ One reason for suboptimal asthma control is nonadherence to prescribed controller therapy, ${ }^{95,96}$ which could be either unintentional or intentional (Figure 1). Unintentional reasons include poor inhaler technique, forgetfulness, or inadequate understanding of instructions by patients or caregivers. ${ }^{97,98}$ It has 


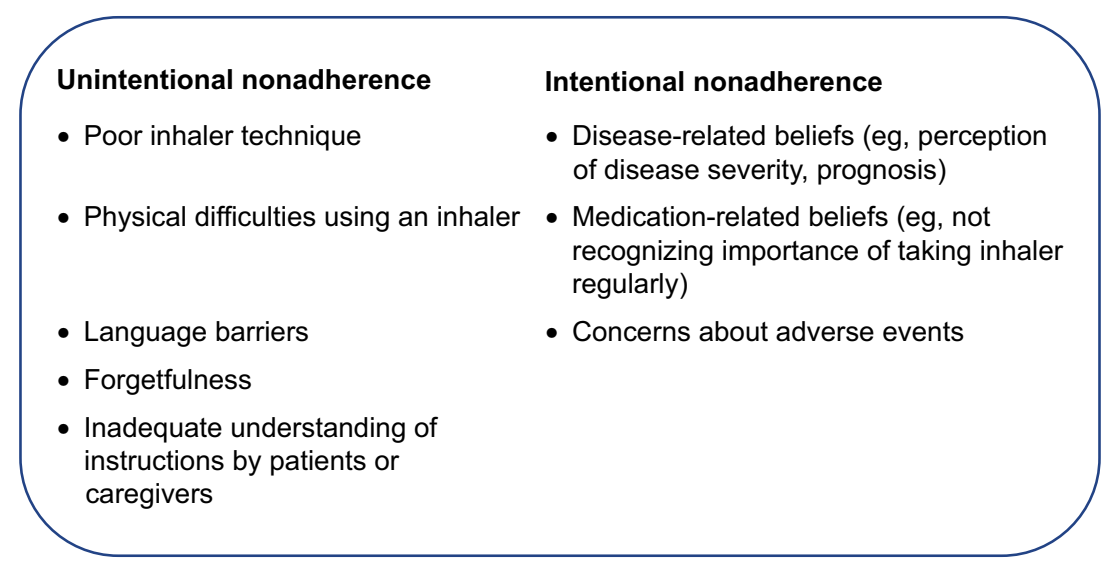

Figure I Reasons for unintentional or intentional nonadherence. Note: Data from these studies. ${ }^{97,98,101}$

been shown that control worsens as the number of mistakes in technique increases. ${ }^{99}$ Additionally, Hodder et al have reported that ease and convenience of use are some of the characteristics that affect patients' perceptions of their inhaler devices. ${ }^{100}$ Intentional reasons could be driven by factors such as disease- or medication-related beliefs, or concerns about adverse effects. ${ }^{101}$ Here, effective patient/caregiver-clinician communication, as advocated by the GINA report, can play an important role. ${ }^{8}$ Eliciting a patient's or caregiver's views on a treatment could help to highlight and guide discussion when addressing possible perceptual barriers, reasons for nonadherence, and practical barriers such as poor inhaler technique. Improved treatment adherence may also be conferred by shared decision-making regarding treatment. Findings from a randomized study by the Better Outcomes of Asthma Treatment group, assessing the effect of shared decision-making on treatment adherence and clinical outcomes in over 600 adults with poorly controlled asthma, demonstrate that conciliation of patient-preferred therapy choices significantly improves treatment adherence and clinical outcomes. ${ }^{102}$

Another factor that may influence therapy choice is device preference. Currently available inhalers include metered-dose inhalers (MDIs), which can be pressurized (pMDI) or breath-actuated, and dry powder inhalers (DPIs), each of which requires a different pattern of inhalation for optimal drug delivery to the lungs. ${ }^{98}$ MDIs are often used incorrectly, ${ }^{99}$ with a study finding that between $28 \%$ and $68 \%$ of patients following the correct technique do not use them well enough to benefit from the medication. ${ }^{103}$ Fink and Rubin ${ }^{103}$ and McFadden ${ }^{104}$ have also shown that many patients lack coordination for the split-second timing required between beginning a slow inhalation and activation of a
pMDI. However, aerosols with a smaller particle size exiting at a low velocity may help to overcome problems with poor coordination. ${ }^{105}$

Tiotropium Respimat ${ }^{\circledR}$ is approved for once-daily administration, most likely supporting adherence to a medication plan rather than a twice-daily regimen. The aerosol cloud generated by the Respimat ${ }^{\circledR}$ Soft Mist ${ }^{\mathrm{TM}}$ inhaler contains a higher fraction of fine particles that exit the inhaler more slowly and last for a longer time than most pMDIs or DPIs. ${ }^{106,107}$ These properties translate into higher lung deposition and may mean that drug delivery and efficacy may be improved with Respimat ${ }^{\circledR}$ in patients who have difficulties actuating and coordinating inhalation when using a pMDI. ${ }^{107}$ Reported adherence to inhalers in children and adolescents can be as low as 50\%, dropping to less than $30 \%$ in those aged 16-17 years. ${ }^{108}$ Characteristics of the inhalers such as mechanism of action were one of the factors affecting adherence in adolescents. ${ }^{108}$ Involving the adolescent patients in selecting their inhaler device has been suggested as a possible option to facilitate adherence. Findings from a patient questionnaire designed to examine preference for, and satisfaction with, inhaler devices in COPD and asthma showed that patients were more willing to continue to use Respimat ${ }^{\circledR}$ vs a hydrofluoroalkane pMDI. Respimat ${ }^{\circledR}$ also had significantly higher satisfaction ratings than other inhalers. ${ }^{109}$ The inhaler device was easier to use, and inhalation of a single dose was shown to provide bronchodilator efficacy over a 24-hour period in patients with symptomatic asthma in a similar manner to twice-daily dosing. ${ }^{56}$ The Soft Mist ${ }^{\mathrm{TM}}$ inhaler is suitable for use by all age groups, as demonstrated in the tiotropium clinical trial program. In addition, a handling study to assess the use of this inhaler in children aged $\leq 5$ years concluded its suitability for this age group, although those younger 
than 5 years are advised to add a valved holding chamber to complement its use. ${ }^{110}$

\section{Shared decision-making in asthma}

A survey of adult asthma patients in a large health maintenance organization reported that $30 \%$ of patients were dissatisfied with their current treatment. Dissatisfaction was significantly associated with poor asthma control, patientprovider communication problems, and the patients' belief in their medication. ${ }^{111,112}$ For example, $16 \%$ of those who had good asthma control were dissatisfied compared with $70 \%$ of those who had poor control. Furthermore, the odds of treatment dissatisfaction were up to eight times higher among patients who reported uncertainty about the efficacy of their medication or their ability to take the medication as directed than those without these management problems. Of those with patient-provider issues, half (49.8\%) were observed among those who reported that their physician did not involve them in treatment decisions. These findings further highlight the importance of patient/caregiver-clinician communication and shared decision-making in the treatment of asthma.

\section{Cost-effectiveness}

Uncontrolled asthma has a negative impact on health status and work productivity and is associated with increased health care costs. ${ }^{113}$ Asthma costs directly increase with increasing lack of disease control. Between $80 \%$ and $90 \%$ of patients had uncontrolled asthma, as determined by The Epidemiology and Natural History of Asthma: Outcomes and Treatment Regimens study, and their costs were more than double those of patients with controlled asthma. ${ }^{114}$ Furthermore, pediatric asthma confers a considerable socioeconomic burden in terms of increased school absences, reduced performance of patients, and missed workdays of caregivers. ${ }^{5}$ Cost-effectiveness is an important aspect when considering new treatment options and their positioning in therapeutic management. Willson et al developed a Markov model to estimate the cost-effectiveness of tiotropium add-on therapy in patients with uncontrolled asthma despite treatment with ICS/LABA from the perspective of the UK National Health Service. ${ }^{115,116}$ Using data from two clinical trials in adult patients with severe asthma, the model considered asthma control and exacerbations, and analyzed cost and qualityadjusted life-years (QALYs). ${ }^{115,116}$ The results showed that tiotropium was cost-effective when added to usual care, generating an incremental 0.19 QALYs and £5,389 in costs over a lifetime horizon, resulting in an incremental cost-effectiveness ratio of $£ 28,383$ per QALY gained. ${ }^{116}$ Other studies conducted in Poland and Portugal also confirmed the cost-effectiveness of tiotropium add-on therapy in treating adults with uncontrolled asthma. ${ }^{117,118}$ A more recent study compared the cost-effectiveness of tiotropium against another add-on therapy option, omalizumab, in patients with uncontrolled severe allergic asthma. ${ }^{119}$ The authors reported lower total discounted costs with tiotropium compared with omalizumab, as well as lower expected values of model outcomes over 10 years in relation to number of nonsevere exacerbation weeks. ${ }^{119}$ Further cost-effectiveness analyses, particularly with biologic therapies, will help to clarify the true cost-effectiveness of tiotropium add-on therapy. With the emergence of novel therapies for asthma that present exciting possibilities for achieving disease control, it is important to critically assess the cost-effectiveness of these options.

\section{Conclusion}

Asthma is a chronic disease that confers a considerable burden on individual patient quality of life, as well as on global health and socioeconomics. Great advances have been made in asthma treatment and management; however, there is still a population of patients who remain difficult to control. LAMAs as add-on therapy are proving effective in achieving asthma control in patients with asthma. The extensive study of tiotropium, as part of a structured program of large-scale trials, demonstrated its efficacy and safety in improving lung function as add-on therapy to ICS \pm LABA in patients of all ages across a broad spectrum of severities. Tiotropium is cost-effective and, unlike biologics, has been shown to be efficacious in all asthma phenotypes, irrespective of patients' baseline characteristics and allergic status. Therefore, in adults, adolescents, and children with severe asthma who experienced one or more exacerbations in the previous year, tiotropium is a suitable alternative add-on treatment to ICS, which should be considered ahead of interventions that require phenotyping. Tiotropium may also provide a much-needed alternative for children who are uncontrolled with ICS \pm LABA and who would otherwise require higher ICS doses and specialist referral.

\section{Acknowledgments}

Medical writing assistance, in the form of the preparation and revision of the draft manuscript, was supported financially by Boehringer Ingelheim and provided by Martina Stagno d'Alcontres, PhD, of MediTech Media, under the authors' conceptual direction and based on feedback from the authors. Boehringer Ingelheim was given the opportunity to review 
the manuscript for factual accuracy only. The authors would like to thank Kjeld Hansen, a member of the Patient Ambassador Group for the European Lung Foundation, for his input to the video summary for this manuscript.

\section{Author contributions}

All authors contributed to data analysis, drafting and revising the article, gave final approval of the version to be published, and agree to be accountable for all aspects of the work.

\section{Disclosure}

The authors declare the following potential conflicts of interest with respect to the research, authorship, and/or publication of this article: RB has received grants and personal fees from Boehringer Ingelheim, GlaxoSmithKline, Novartis, and Roche, and personal fees from AstraZeneca, Chiesi, and Teva. EH declares that there is no conflict of interest regarding the publication of this article.

\section{References}

1. World Health Organization. Asthma fact sheet 307. Available from: http://www.who.int/mediacentre/factsheets/fs307/en/. Accessed January 24, 2018.

2. Global Burden of Disease 2016 Disease and Injury Incidence and Prevalence Collaborators. Global, regional, and national incidence, prevalence, and years lived with disability for 328 diseases and injuries for 195 countries, 1990-2016: a systematic analysis for the Global Burden of Disease Study 2016. Lancet. 2017;390(10100):1211-1259.

3. Demoly P, Paggiaro P, Plaza V, et al. Prevalence of asthma control among adults in France, Germany, Italy, Spain and the UK. Eur Respir Rev. 2009;18(112):105-112.

4. Price D, Mathieson N, Mulgirigama A, et al. P17 The burden of ICS/ LABA-treated asthma patients in the UK adult population. Thorax. 2013;68(Supp1 3):A82.

5. Schmier JK, Manjunath R, Halpern MT, Jones ML, Thompson K, Diette GB. The impact of inadequately controlled asthma in urban children on quality of life and productivity. Ann Allergy Asthma Immunol. 2007;98(3):245-251.

6. Price D, Fletcher M, van der Molen T. Asthma control and management in 8,000 European patients: the REcognise Asthma and LInk to Symptoms and Experience (REALISE) survey. NPJ Prim Care Respir Med. 2014;24(1):14009.

7. Custovic A, Johnston SL, Pavord I, et al. EAACI position statement on asthma exacerbations and severe asthma. Allergy. 2013;68(12): $1520-1531$.

8. Global Initiative for Asthma. GINA report: global strategy for asthma management and prevention. Available from: http://ginasthma. org/2018-gina-report-global-strategy-for-asthma-management-andprevention/. Accessed October 22, 2018.

9. Jenkins C. Tiotropium in adults with asthma: current management strategies. Ther Clin Risk Manag. In press 2018.

10. Goldstein S. Clinical efficacy and safety of anticholinergic therapies in pediatric patients. Ther Clin Risk Manag. In press 2018.

11. Boehringer Ingelheim. Asthma: Expanded indication for SPIRIVA ${ }^{\circledR}$ Respimat ${ }^{\circledR}$ for people 6 years and older. Available from: https://www. boehringer-ingelheim.com/press-release/expanded-asthma-indicationspiriva-respimat-eu. Accessed October 22, 2018.

12. U.S. Food and Drug Administration. Prescribing information for Spiriva ${ }^{\circledR}$ Respimat $^{\mathbb{B}}$ (tiotropium bromide) inhalation spray, for oral inhalation. Available from: https://www.accessdata.fda.gov/drugsatfda_docs/ label/2017/021936s007lbl.pdf. Accessed October 22, 2018.
13. Kerstjens HA, Engel M, Dahl R, et al. Tiotropium in asthma poorly controlled with standard combination therapy. N Engl J Med. 2012; 367(13):1198-1207.

14. Kerstjens HA, Casale TB, Bleecker ER, et al. Tiotropium or salmeterol as add-on therapy to inhaled corticosteroids for patients with moderate symptomatic asthma: two replicate, double-blind, placebo-controlled, parallel-group, active-comparator, randomised trials. Lancet Respir Med. 2015;3(5):367-376.

15. Hamelmann E, Bateman ED, Vogelberg C, et al. Tiotropium add-on therapy in adolescents with moderate asthma: a 1-year randomized controlled trial. J Allergy Clin Immunol. 2016;138(2):441-450.

16. Hamelmann E, Bernstein JA, Vandewalker M, et al. A randomised controlled trial of tiotropium in adolescents with severe symptomatic asthma. Eur Respir J. 2017;49(1):1601100.

17. Vogelberg C, Engel M, Laki I, et al. Tiotropium add-on therapy improves lung function in children with symptomatic moderate asthma. J Allergy Clin Immunol Pract. 2018;6(6):2160-2162.

18. Szefler SJ, Murphy K, Harper T, et al. A phase III randomized controlled trial of tiotropium add-on therapy in children with severe symptomatic asthma. J Allergy Clin Immunol. 2017;140(5):1277-1287.

19. Vrijlandt E, El Azzi G, Vandewalker M, et al. Safety and efficacy of tiotropium in children aged 1-5 years with persistent asthmatic symptoms: a randomised, double-blind, placebo-controlled trial. Lancet Respir Med. 2018;6(2):127-137.

20. Rodrigo GJ, Neffen H. Efficacy and safety of tiotropium in school-age children with moderate-to-severe symptomatic asthma: a systematic review. Pediatr Allergy Immunol. 2017;28(6):573-578.

21. Vogelberg C, Moroni-Zentgraf P, Leonaviciute-Klimantaviciene M, et al. A randomised dose-ranging study of tiotropium Respimat ${ }^{\circledR}$ in children with symptomatic asthma despite inhaled corticosteroids. Respir Res. 2015;16(1):20.

22. U.S. Food and Drug Administration. Prescribing information for XOLAIR $^{\circledR}$ (omalizumab). Available from: https://www.gene.com/ download/pdf/xolair_prescribing.pdf. Accessed November 1, 2017.

23. Pharma T. CINQAIR - Summary of Product Characteristics. Available from: https://www.accessdata.fda.gov/drugsatfda_docs/ label/2016/7610331bl.pdf. Accessed June 1, 2018.

24. GlaxoSmithKline UK. NUCALA summary of product characteristics. Available from: https://www.accessdata.fda.gov/drugsatfda_docs/ label/2016/761033lbl.pdf. Accessed June 1, 2018.

25. Ortega HG, Liu MC, Pavord ID, et al. Mepolizumab treatment in patients with severe eosinophilic asthma. $N$ Engl J Med Overseas Ed. 2014;371(13):1198-1207.

26. Bjermer L, Lemiere C, Maspero J, Weiss S, Zangrilli J, Germinaro M. Reslizumab for inadequately controlled asthma with elevated blood eosinophil levels: a randomized Phase 3 Study. Chest. 2016;150(4): 789-798.

27. AstraZeneca plc. AstraZeneca receives EU approval of Fasenra for severe eosinophilic asthma. Available from: https://www.astrazeneca. com/media-centre/press-releases/2018/astrazeneca-receives-euapproval-of-fasenra-for-severe-eosinophilic-asthma-10012018.html. Accessed June 1, 2018.

28. Castro M, Corren J, Pavord ID, et al. Dupilumab efficacy and safety in moderate-to-severe uncontrolled asthma. N Engl J Med. 2018; 378(26):2486-2496.

29. Rabe KF, Nair P, Brusselle G, et al. Efficacy and safety of dupilumab in glucocorticoid-dependent severe asthma. N Engl J Med. 2018;378(26): 2475-2485.

30. Wenzel S, Castro M, Corren J, et al. Dupilumab efficacy and safety in adults with uncontrolled persistent asthma despite use of mediumto-high-dose inhaled corticosteroids plus a long-acting $\beta 2$ agonist: a randomised double-blind placebo-controlled pivotal phase $2 \mathrm{~b}$ doseranging trial. Lancet. 2016;388(10039):31-44.

31. Caruso M, Morjaria J, Emma R, Amaradio MD, Polosa R. Biologic agents for severe asthma patients: clinical perspectives and implications. Intern Emerg Med. 2018;13(2):155-176.

32. Chang A, Bossé Y. Targeting single molecules in asthma benefits few. Trends Mol Med. 2016;22(11):935-945. 
33. Walsh LJ, Wong CA, Oborne J, et al. Adverse effects of oral corticosteroids in relation to dose in patients with lung disease. Thorax. 2001;56(4):279-284.

34. Lefebvre P, Duh MS, Lafeuille MH, et al. Acute and chronic systemic corticosteroid-related complications in patients with severe asthma. J Allergy Clin Immunol. 2015;136(6):1488-1495.

35. Gibson PG, Yang IA, Upham JW, et al. Effect of azithromycin on asthma exacerbations and quality of life in adults with persistent uncontrolled asthma (AMAZES): a randomised, double-blind, placebo-controlled trial. Lancet. 2017;390(10095):659-668.

36. Wahidi MM, Kraft M. Bronchial thermoplasty for severe asthma. Am J Respir Crit Care Med. 2012;185(7):709-714.

37. Donohue JF, Wise R, Busse WW, et al. Efficacy and safety of ipratropium bromide/albuterol compared with albuterol in patients with moderate-to-severe asthma: a randomized controlled trial. BMC Pulm Med. 2016;16(1):65.

38. Cazzola M, Ora J, Rogliani P, Matera MG. Role of muscarinic antagonists in asthma therapy. Expert Rev Respir Med. 2017;11(3) 239-253.

39. Meurs H, Oenema TA, Kistemaker LE, Gosens R. A new perspective on muscarinic receptor antagonism in obstructive airways diseases. Curr Opin Pharmacol. 2013;13(3):316-323.

40. Boehringer Ingelheim International GmbH. Spiriva Respimat 2.5 microgram, solution for inhalation - Summary of Product Characteristics, Europe. Available from: https://www.boehringer-ingelheim.com/ products/prescription_medicines/respiratory/asthma/spiriva/public/ images/14-3946-Blatter-SPC-Spiriva-ERS.pdf. Accessed June 22, 2014.

41. Heredia JL. Tiotropium bromide: an update. Open Respir Med J. 2009; 3(1):43-52.

42. Barnes PJ. The pharmacological properties of tiotropium. Chest. 2000; 117(2 Suppl):63S-66S.

43. Koumis T, Samuel S. Tiotropium bromide: a new long-acting bronchodilator for the treatment of chronic obstructive pulmonary disease. Clin Ther. 2005;27(4):377-392.

44. Moulton BC, Fryer AD. Muscarinic receptor antagonists, from folklore to pharmacology; finding drugs that actually work in asthma and COPD. Br J Pharmacol. 2011;163(1):44-52.

45. Ward MJ, Fentem PH, Smith WH, Davies D. Ipratropium bromide in acute asthma. Br Med J (Clin Res Ed). 1981;282(6264):598-600.

46. Lougheed MD, Lemière C, dell SD, et al. Canadian Thoracic Society Asthma Management Continuum - 2010 Consensus Summary for children six years of age and over, and adults. Can Respir J. 2010; 17(1):15-24.

47. Griffiths B, Ducharme FM. Combined inhaled anticholinergics and short-acting beta2-agonists for initial treatment of acute asthma in children. Cochrane Database Syst Rev. 2013;21(8):CD000060.

48. Rodrigo GJ, Castro-Rodriguez JA. Anticholinergics in the treatment of children and adults with acute asthma: a systematic review with meta-analysis. Thorax. 2005;60(9):740-746.

49. Jolobe OM. Asthma vs. non-specific reversible airflow obstruction: clinical features and responsiveness to anticholinergic drugs. Respiration. 1984;45(3):237-242.

50. Mcdonald NJ, Bara AI. Anticholinergic therapy for chronic asthma in children over two years of age. Cochrane Database Syst Rev. 2003;3: CD003535.

51. Westby M, Benson M, Gibson P. Anticholinergic agents for chronic asthma in adults. Cochrane Database Syst Rev. 2004;3:CD003269.

52. Beeh KM, Moroni-Zentgraf $\mathrm{P}$, Ablinger O, et al. Tiotropium Respimat ${ }^{\mathbb{R}}$ in asthma: a double-blind, randomised, dose-ranging study in adult patients with moderate asthma. Respir Res. 2014;15(1):61.

53. Kerstjens HA, Disse B, Schröder-Babo W, et al. Tiotropium improves lung function in patients with severe uncontrolled asthma: a randomized controlled trial. J Allergy Clin Immunol. 2011;128(2):308-314.

54. Bateman ED, Kornmann O, SchmidtP, Pivovarova A, Engel M, Fabbri LM. Tiotropium is noninferior to salmeterol in maintaining improved lung function in B16-Arg/Arg patients with asthma. J Allergy Clin Immunol. 2011;128(2):315-322.
55. Beeh KM, Kirsten AM, Dusser D, et al. Pharmacodynamics and pharmacokinetics following once-daily and twice-daily dosing of Tiotropium Respimat ${ }^{\mathbb{R}}$ in asthma using standardized samplecontamination avoidance. J Aerosol Med Pulm Drug Deliv. 2016; 29(5):406-415.

56. Timmer W, Moroni-Zentgraf P, Cornelissen P, Unseld A, Pizzichini E, Buhl R. Once-daily tiotropium Respimat ${ }^{\circledR} 5 \mu \mathrm{g}$ is an efficacious $24-\mathrm{h}$ bronchodilator in adults with symptomatic asthma. Respir Med. 2015; 109(3):329-338.

57. Paggiaro P, Halpin DM, Buhl R, et al. The effect of tiotropium in symptomatic asthma despite low- to medium-dose inhaled corticosteroids: a randomized controlled trial. J Allergy Clin Immunol Pract. 2016; 4(1):104-113.

58. Vogelberg C, Engel M, Moroni-Zentgraf P, et al. Tiotropium in asthmatic adolescents symptomatic despite inhaled corticosteroids: a randomised dose-ranging study. Respir Med. 2014;108(9):1268-1276.

59. Ohta K, Ichinose M, Tohda Y, et al. Long-term once-daily tiotropium Respimat $^{\circledR}$ is well tolerated and maintains efficacy over 52 weeks in patients with symptomatic asthma in Japan: a randomised, placebocontrolled study. PLoS One. 2015;10(4):e0124109.

60. Peters SP, Kunselman SJ, Icitovic N, et al. Tiotropium bromide step-up therapy for adults with uncontrolled asthma. N Engl J Med. 2010; 363(18):1715-1726.

61. Sharma A, Schmid M, Rapp B, Moroni-Zentgraf P, Engel M. Pharmacokinetics of tiotropium in asthma patients from three paediatric clinical trials. Eur Respir J. 2016;48:PA316.

62. Kerstjens HA, Moroni-Zentgraf P, Tashkin DP, et al. Tiotropium improves lung function, exacerbation rate, and asthma control, independent of baseline characteristics including age, degree of airway obstruction, and allergic status. Respir Med. 2016;117:198-206.

63. Casale TB, Bateman ED, Aalbers R, et al. Once-daily tiotropium Respimat add-on therapy improves lung function and asthma control in moderate symptomatic asthma, independent of baseline characteristics. Eur Respir J. 2017;50:PA647.

64. Vandewalker M, Vogelberg C, Hamelmann E, et al. Tiotropium Respimat $^{\circledR}$ add-on therapy improves lung function in adolescents and children with moderate symptomatic asthma, irrespective of IgE levels and eosinophil count. Poster P521 presented at: The American Thoracic Society International Conference; May 19-24, 2016; Washington, DC.

65. Goldstein S, Vogelberg C, Hamelmann E, et al. Tiotropium Respimat ${ }^{\circledR}$ add-on therapy is effective in children and adolescents with severe symptomatic asthma, irrespective of immunoglobulin E levels and eosinophil count. Poster P520 presented at: The American Thoracic Society International Conference; May 19-24, 2016; Washington, DC.

66. Hamelmann E, Vogelberg C, Voelker B, et al. Tiotropium add-on therapy improves lung function in children and adolescents with moderate and severe symptomatic asthma, independent of markers of allergic status. Allergy. 2017;72:S1030659.

67. Kang JY, Rhee CK, Kim JS, et al. Effect of tiotropium bromide on airway remodeling in a chronic asthma model. Ann Allergy Asthma Immunol. 2012;109(1):29-35.

68. Ohta S, Oda N, Yokoe T, et al. Effect of tiotropium bromide on airway inflammation and remodelling in a mouse model of asthma. Clin Exp Allergy. 2010;40(8):1266-1275.

69. Bosnjak B, Tilp C, Tomsic C, et al. Tiotropium bromide inhibits relapsing allergic asthma in BALB/c mice. Pulm Pharmacol Ther. 2014; 27(1):44-51.

70. Lee LA, Briggs A, Edwards LD, Yang S, Pascoe S. A randomized, three-period crossover study of umeclidinium as monotherapy in adult patients with asthma. Respir Med. 2015;109(1):63-73.

71. Yang S, Goyal N, Beerahee M, Trivedi R, Lee L, Pascoe S. Doseresponse modelling of umeclidinium and fluticasone furoate/ umeclidinium in asthma. Eur J Clin Pharmacol. 2015;71(9):1051-1058.

72. Lee LA, Yang S, Kerwin E, Trivedi R, Edwards LD, Pascoe S. The effect of fluticasone furoate/umeclidinium in adult patients with asthma: a randomized, dose-ranging study. Respir Med. 2015;109(1):54-62. 
73. ClinicalTrials.gov (US). A phase III parallel group study, comparing the efficacy, safety and tolerability of the fixed dose combination (FDC) of fluticasone furoate+umeclidinium bromide+vilanterol (FF/UMEC/ $\mathrm{VI})$ with the FDC of FF/VI in subjects with inadequately controlled asthma (NCT02924688). Available from: https://clinicaltrials.gov/ct2/ show/NCT02924688. Accessed October 11, 2017.

74. Blais CM, Davis BE, Cockcroft DW. Duration of bronchoprotection of the long-acting muscarinic antagonists tiotropium \& glycopyrronium against methacholine-induced bronchoconstriction in mild asthmatics. Respir Med. 2016;118:96-101.

75. Hansel TT, Neighbour H, Erin EM, et al. Glycopyrrolate causes prolonged bronchoprotection and bronchodilatation in patients with asthma. Chest. 2005;128(4):1974-1979.

76. Antoniu SA. Aclidinium bromide in experimental asthma. Expert Opin Investig Drugs. 2011;20(6):871-873.

77. Damera G, Jiang M, Zhao H, et al. Aclidinium bromide abrogates allergen-induced hyperresponsiveness and reduces eosinophilia in murine model of airway inflammation. Eur J Pharmacol. 2010; 649(1-3):349-353.

78. Bateman ED, Boushey HA, Bousquet J, et al. Can guideline-defined asthma control be achieved? The Gaining Optimal Asthma Control study. Am J Respir Crit Care Med. 2004;170(8):836-844.

79. Tan KS, Grove A, Mclean A, Gnosspelius Y, Hall IP, Lipworth BJ. Systemic corticosteriod rapidly reverses bronchodilator subsensitivity induced by formoterol in asthmatic patients. Am J Respir Crit Care Med. 1997;156(1):28-35.

80. Yates DH, Sussman HS, Shaw MJ, Barnes PJ, Chung KF. Regular formoterol treatment in mild asthma. Effect on bronchial responsiveness during and after treatment. Am J Respir Crit Care Med. 1995;152(4): $1170-1174$.

81. Evans DJ, Kew KM, Anderson DE, Boyter AC. Long-acting muscarinic antagonists (LAMA) added to inhaled corticosteroids (ICS) versus higher dose ICS for adults with asthma. Cochrane Database Syst Rev. 2015;21(7):CD011437.

82. Kew KM, Evans DJ, Allison DE, Boyter AC. Long-acting muscarinic antagonists (LAMA) added to inhaled corticosteroids (ICS) versus addition of long-acting beta2-agonists (LABA) for adults with asthma. Cochrane Database Syst Rev. 2015;2(6):CD011438.

83. Peters SP, Bleecker ER, Kunselman SJ, et al. Predictors of response to tiotropium versus salmeterol in asthmatic adults. $J$ Allergy Clin Immunol. 2013;132(5):1068-1074.

84. Bensch G, Berger WE, Blokhin BM, et al. One-year efficacy and safety of inhaled formoterol dry powder in children with persistent asthma. Ann Allergy Asthma Immunol. 2002;89(2):180-190.

85. Nelson HS, Weiss ST, Bleecker ER, Yancey SW, Dorinsky PM; SMART Study Group. The Salmeterol Multicenter Asthma Research Trial: a comparison of usual pharmacotherapy for asthma or usual pharmacotherapy plus salmeterol. Chest. 2006;129(1):15-26.

86. National Institute for Health and Care Excellence, 2014. Asthma: fluticasone furoate/vilanterol (Relvar Ellipta) combination inhaler. Available from: https://www.nice.org.uk/advice/esnm34/chapter/ Key-points-from-the-evidence. Accessed June 1, 2018.

87. Holgate ST, Bousquet J, Chung KF, et al. Summary of recommendations for the design of clinical trials and the registration of drugs used in the treatment of asthma. Respir Med. 2004;98(6):479-487.

88. Lemanske RF, Mauger DT, Sorkness CA, et al. Step-up therapy for children with uncontrolled asthma receiving inhaled corticosteroids. N Engl J Med Overseas Ed. 2010;362(11):975-985.

89. Castro-Rodriguez JA, Rodrigo GJ. The role of inhaled corticosteroids and montelukast in children with mild-moderate asthma: results of a systematic review with meta-analysis. Arch Dis Child. 2010;95(5):365-370.

90. Chauhan BF, Ben Salah R, Ducharme FM. Addition of anti-leukotriene agents to inhaled corticosteroids in children with persistent asthma. Cochrane Database Syst Rev. 2013;2(10):CD009585.

91. Zhang L, Prietsch SO, Ducharme FM. Inhaled corticosteroids in children with persistent asthma: effects on growth. Evid Based Child Health. 2014;9(4):829-930.
92. Pruteanu AI, Chauhan BF, Zhang L, Prietsch SO, Ducharme FM. Inhaled corticosteroids in children with persistent asthma: doseresponse effects on growth. Cochrane Database Syst Rev. 2014;17(7): CD009878.

93. Rabe KF, Adachi M, Lai CK, et al. Worldwide severity and control of asthma in children and adults: the global asthma insights and reality surveys. J Allergy Clin Immunol. 2004;114(1):40-47.

94. Fitzgerald JM, Boulet LP, Mcivor RA, Zimmerman S, Chapman KR. Asthma control in Canada remains suboptimal: the Reality of Asthma Control (TRAC) study. Can Respir J. 2006;13(5):253-259.

95. Spector S. Noncompliance with asthma therapy - are there solutions? J Asthma. 2000;37(5):381-388.

96. Suissa S, Ernst P, Benayoun S, Baltzan M, Cai B. Low-dose inhaled corticosteroids and the prevention of death from asthma. $N$ Engl $J$ Med Overseas Ed. 2000;343(5):332-336.

97. Inhaler Error Steering Committee, Price D, Bosnic-Anticevich S, et al. Inhaler competence in asthma: common errors, barriers to use and recommended solutions. Respir Med. 2013;107(1):37-46.

98. Haughney J, Price D, Kaplan A, et al. Achieving asthma control in practice: understanding the reasons for poor control. Respir Med. 2008; 102(12):1681-1693.

99. Giraud V, Roche N. Misuse of corticosteroid metered-dose inhaler is associated with decreased asthma stability. Eur Respir J. 2002;19(2): 246-251.

100. Hodder R, Reese PR, Slaton T. Asthma patients prefer Respimat Soft Mist Inhaler to Turbuhaler. Int J Chron Obstruct Pulmon Dis. 2009;4:225-232.

101. Gadkari AS, Mchorney CA. Unintentional non-adherence to chronic prescription medications: how unintentional is it really? BMC Health Serv Res. 2012;12(1):98.

102. Wilson SR, Strub P, Buist AS, et al. Shared treatment decision making improves adherence and outcomes in poorly controlled asthma. Am J Respir Crit Care Med. 2010;181(6):566-577.

103. Fink JB, Rubin BK. Problems with inhaler use: a call for improved clinician and patient education. Respir Care. 2005;50(10):1374-1375.

104. Mcfadden ER. Improper patient techniques with metered dose inhalers: clinical consequences and solutions to misuse. $J$ Allergy Clin Immunol. 1995;96(2):278-283.

105. Anderson P. Use of Respimat Soft Mist inhaler in COPD patients. Int J Chron Obstruct Pulmon Dis. 2006;1(3):251-259.

106. Moroni-Zentgraf P. Impact of patient needs on design and usage of an inhalation device in respiratory medicine. Respir Drug Delivery Euro. 2013;1:141-152.

107. Watchel H, Kattenbeck K, Dunne S. The Respimat ${ }^{\circledR}$ development story: patient-centered innovation. Pulm Ther. 2017;3:19-30.

108. de Simoni A, Horne R, Fleming L, Bush A, Griffiths C. What do adolescents with asthma really think about adherence to inhalers? Insights from a qualitative analysis of a UK online forum. BMJ Open. 2017;7(6):e015245.

109. Schürmann W, Schmidtmann S, Moroni P, Massey D, Qidan M. Respimat Soft Mist inhaler versus hydrofluoroalkane metered dose inhaler: patient preference and satisfaction. Treat Respir Med. 2005; 4(1):53-61.

110. Kamin W, Frank M, Kattenbeck S, Moroni-Zentgraf P, Wachtel H, Zielen S. A Handling study to assess use of the Respimat ${ }^{(\mathbb{})}$ Soft Mist ${ }^{\mathrm{TM}}$ inhaler in children under 5 years old. J Aerosol Med Pulm Drug Deliv. 2015;28(5):372-381.

111. Markson LE, Vollmer WM, Fitterman L, et al. Insight into patient dissatisfaction with asthma treatment. Arch Intern Med. 2001;161(3): 379-384.

112. Small M, Anderson P, Vickers A, Kay S, Fermer S. Importance of inhaler-device satisfaction in asthma treatment: real-world observations of physician-observed compliance and clinical/patient-reported outcomes. Adv Ther. 2011;28(3):202-212.

113. Accordini S, Corsico AG, Braggion M, et al. The cost of persistent asthma in Europe: an international population-based study in adults. Int Arch Allergy Immunol. 2013;160(1):93-101. 
114. Chipps BE, Zeiger RS, Borish L, et al. Key findings and clinical implications from the epidemiology and natural history of asthma: outcomes and treatment regimens (TENOR) study. J Allergy Clin Immunol. 2012;130(2):e10:332-342.

115. Willson J, Bateman ED, Pavord I, Lloyd A, Krivasi T, Esser D. Cost effectiveness of tiotropium in patients with asthma poorly controlled on inhaled glucocorticosteroids and long-acting $\beta$-agonists. Appl Health Econ Health Policy. 2014;12(4):447-459.

116. Willson J, Bateman ED, Pavord I, Lloyd A, Krivasi T, Esser D. Erratum to: cost effectiveness of tiotropium in patients with asthma poorly controlled on inhaled glucocorticosteroids and long-acting $\beta$-agonists. Appl Health Econ Health Policy. 2016;14(1):119-125.
117. Pawlik M, Walczak J, Pieniazek I. Economic evaluation of tiotropium administrated through the Respimat inhaler as add-on therapy in patients with uncontrolled severe asthma in Poland. Value Health. 2015;18(7):A502.

118. Silva Miguel L, Manaças M, Pinheiro B. Economic evaluation of tiotropium for severe persistent asthma in Portugal. Value Health. 2015;18(7):A502.

119. Zafari Z, Sadatsafavi M, Mark FitzGerald J; Canadian Respiratory Research Network. Cost-effectiveness of tiotropium versus omalizumab for uncontrolled allergic asthma in US. Cost Eff Resour Alloc. 2018;16(1):3.

\section{Publish your work in this journal}

Therapeutics and Clinical Risk Management is an international, peerreviewed journal of clinical therapeutics and risk management, focusing on concise rapid reporting of clinical studies in all therapeutic areas, outcomes, safety, and programs for the effective, safe, and sustained use of medicines. This journal is indexed on PubMed Central, CAS,

\section{Dovepress}

EMBase, Scopus and the Elsevier Bibliographic databases. The manuscript management system is completely online and includes a very quick and fair peer-review system, which is all easy to use. Visit $\mathrm{http}: / / \mathrm{www}$.dovepress.com/testimonials.php to read real quotes from published authors.

Submit your manuscript here: http://www.dovepress.com/therapeutics-and-clinical-risk-management-journal 